\title{
Retraction Note to: The Critical Role of SRPK1 in EMT of Human Glioblastoma in the Spinal Cord
}

\author{
Zhengbu Liao ${ }^{1} \cdot$ Jing $\mathrm{Wu}^{2} \cdot$ Mingjun $\mathrm{Wu}^{3} \cdot \mathrm{Yi} \mathrm{Yan}{ }^{1} \cdot$ Haiquan Wang ${ }^{1} \cdot$ \\ Chongjie Cheng ${ }^{1} \cdot$ Wenyuan Tang ${ }^{1}$
}

Published online: 21 June 2017

(C) Springer Science+Business Media, LLC 2017

Retraction Note to: Mol Neurobiol (2017) 54:1818-1824

DOI 10.1007/s12035-016-9784-7

This article has been retracted at the request of the Editorin-Chief and the Publisher per the Committee on Publication Ethics guidelines. There is strong reason to believe that the peer review process was compromised. As such the validity of the content of this article cannot be verified.

The online version of the original article can be found at http://dx.doi.org/10. 1007/s12035-016-9784-7

\footnotetext{
Zhengbu Liao

liaozhengbu163@163.com

1 Department of Neurosurgery, The First Affiliated Hospital of Chongqing Medical University, ChongQing 400016, China

2 Intensive Care Unit, The Second Affiliated Hospital of Chongqing Medical University, ChongQing 400010, China

3 Institute of Molecular Biology, Chongqing Medical University, ChongQing 400016, China
} 